20. RID - Expert-RA research (2010) Report: Vliyanie kachestva korporativnogo upravleniya na effectivnost deyatelnosti kompanii. [The impact of corporate governance quality on a company's effectiveness]. Ed.Ivashkovskaya, I.V.

21. Ruzhanskaya L.S. (2010) Raskrytie informatsii rossiyskimi kompaniyami: rezultaty empiricheskogo issledovaniya. [Information disclosure by Russian companies: Empirical research results] . Russian Management Journal, vol. 8, no. 3, pp. 35-56.

22. Sami H., Wang J. and Zhou H. (2011) Corporate Governance and Operating Performance of Chinese Listed Firms. Journal of International Accounting, Auditing and Taxation, vol. 20, no. 8, pp. 106-114.

23. Stepanova A.N. (2007) Korporativnoe upravlenie i korporativnye resultaty: empiricheskie dokazatelstva na opyte stran s rastuschim rynkom kapitala. [Corporate governance and corporate results: Empirical proof from countries with growing capital market] . Journal of Corporate Finance Research, no. 4, pp. 65-75.

24. Strange R., Filatotchev I., Buck T. and Wright M. (2009) Corporate Governance and International Business. Management International Review, vol. 49, no. 4, pp. 395-407.

25. Yiu D., Bruton G.D. and Lu Y. (2005) Understanding business group performance in an emerging economy: Acquiring resources and capabilities in order to prosper. Journal of Management Studies, vol. 41, no. 1, pp. 183-206.

\title{
СТАНОВЛЕНИЕ И РАЗВИТИЕ ПРОЦЕССА КОНВЕРГЕНЦИИ ДВУХ ВИДОВ СТАНДАРТОВ: МСФО И US GAAР
}

\author{
Малофеева Татьяна Николаевна ${ }^{1}$,
}

Общеизвестно, что экономика - это фундамент, на котором стоит государство. И каким оно будет, зависит от характера экономических процессов, происходящих в стране. Одним из факторов благоприятного экономического климата является создание подходящих условий для возникновения и развития транснациональных корпораций (ТНК). Для плодотворной и выгодной работы ТНК необходимы стандарты, в соответствии с которыми компания, во-первых, ведет бухгалтерский учет, а во-вторых, предоставляет финансовую отчетность различным пользователям. Сложность в данном случае заключается, с одной стороны, в том, чтобы вести деятельность компании и предоставлять информацию о финансовых результатах компании в соответствии с принципами принимающих стран, т.е. стран, в которых расположена собственность ТНК; и, с другой стороны, в том, чтобы осуществлять те же действия - только в соответствии с принципами страны базирования, т.е. страны, в которой расположена штабквартира ТНК. В данной работе проводится анализ поэтапного становления и развития процесса конвергенции двух видов стандартов: американских общепринятых стандартов бухгалтерского учета (US GAAP) и международных стандартов финансовой отчетности (МСФО). Выявлено, что в различные периоды скорость конвергенции существенно изменялась, причиной чего являлась смена руководства администрации Белого дома. Определены слабые места МСФО и обоснована готовность мирового сообщества к высокой скорости глобализации.

Ключевые слова: МСФО, американские общепринятые принципы учета, конвергенция, сравнение, глобализация

JEL: M14; M40

\section{Введение}

Начиная с 1960-1970-х годов ученые стали задумываться над преобразованием мира в единую глобальную систему, и уже в 1990-х годах процесс глобализации стал весьма актуальным. Большинство стран стремится к созданию здоровой и устойчивой экономики, что связа-

\footnotetext{
${ }^{1}$ Преподаватель, НИУ «Высшая Школа Экономики» (119049, Россия, г. Москва, ул. Шаболовка, д.26; e-mail: malofeewa@mail.ru).
} 
но с совокупностью различных факторов: это и условия развития малого и среднего бизнеса, которые способствуют формированию среднего класса - основополагающего элемента гражданского общества; и инвестиционный климат - условия, способствующие притоку и оттоку иностранного капитала в страну; и «налоговые условия», предопределяющие создание бизнеса; и создание условий для развития транснациональных корпораций (ТНК), которые являются своеобразным двигателем глобализации; и многие другие факторы. Есть два основных фактора, которые олицетворяют проблему ведения учета и составления отчетности в ТНК: первый заключается в том, что для ведения бухгалтерского учета и предоставления финансовой отчетности в соответствии с принципами двух стран требуется огромное количество денежных, человеческих и временных ресурсов; второй фактор заключается в сложности сопоставления и сравнения принципов двух разных стран. Однако в рамках процесса экономической интеграции и унификации в 1973 г. совместными усилиями профессиональных бухгалтерских организаций 10 стран (Австралия, Канада, Франция, Германия, Мексика, Япония, Нидерланды, Англия, Ирландия и США) был создан Комитет по Международным стандартам финансовой отчетности (International Accounting Standards Committee, далее IASC), который провозгласил своей главной целью унификацию и гармонизацию принципов бухгалтерского учета повсеместно [http://www.iasplus.com/en/resources/ifrsf/history/resource25].

Последовательное развитие этого комитета и расширение базы стандартов, обязательных к применению при составлении и предоставлении финансовой отчетности, являются индикаторами продолжающейся глобализации и стремления IASC преодолеть проблемы THК, которые были перечислены выше.

Главной целью данной работы является анализ поэтапного становления и развития процесса конвергенции двух видов стандартов: американских общепринятых стандартов бухгалтерского учета и МСФО, начиная с момента образования IASC (1973 г.) и заканчивая 2012 г. (исследование процесса конвергенции двух стандартов заканчивается 2012 г. по причине отсутствия надежной и объективной информации за последующий период).

Прежде всего мы рассмотрим образование и начало работы IASC с выпуском первых стандартов (период с 1973 г. по начало 2002 г.). Далее мы проанализируем действия IASC и Комиссии по ценным бумагам и биржам США (Securities and Exchange Commission, далеe SEC) в отношении процесса конвергенции и ее скорость. Забегая вперед, следует отметить, что скорость конвергенции была намного выше в период деятельности администрации Джорджа Буша (2002-2009), в то время как в период работы администрации Барака Обамы (с января 2009 г. по конец 2012 г., так как наш анализ заканчивается именно этим годом) стимулов к развитию и завершению конвергенции было значительно меньше, а следовательно, и скорость конвергенции была маленькой. Таким образом, рассмотрев поэтапное развитие процесса сближения МСФО и US GAAP, мы проанализируем, во-первых, возможные проблемы самих международных стандартов финансовой отчетности, которые призваны быть объединяющей силой стандартов большинства стран: во-вторых, качество американских и международных стандартов; и в-третьих, готовность самого мира к высокой скорости глобализации.

\section{Начало работы IASC (1973-2002)}

Как было упомянуто выше, IASC был образован в 1973 г. с главной целью - разрабатывать и публиковать стандарты бухгалтерского учета, которые связаны с предоставлением публичной финансовой отчетности, и совершенствовать и гармонизировать их. В данной части работы речь пойдет о том, как начинал свою работу IASC, какие изменения претерпела его структура и какие стандарты были первыми.

\section{Структура IASC}

C момента образования IASC это был главный орган, который вырабатывал международные стандарты предоставления финансовой отчетности. Однако это не был в прямом смысле комитет, скорее он представлял собой структуру, состоящую из нескольких компонентов, которые обладали определенными задачами и функциями. 
Первоначально структура IASC выглядела следующим образом. Орган правления IASC, или IASC Board, отвечал за непосредственную разработку стандартов бухгалтерской отчетности, их интерпретацию и составление концептуальной структуры. В этот орган входило только 13 стран-участниц, однако также было возможным вхождение дополнительно одной-трех организаций, которые действовали как внештатные сотрудники. Каждый член или участник IASC Board представлял двух делегатов и одного технического советника, т.е. количество людей, участвующих в дебатах и принимающих решение (голосующих), могло варьироваться от 39 до 48. Кроме того, орган правления мог включать лиц, которые имели только статус наблюдателей, т.е. они могли участвовать в дебатах, но не имели права голосовать; как правило, это были представители Европейской Комиссии, FASB и Международной организации комиссий по ценным бумагам (International Organization of Securities Commissions - IOSCO) [http:// www.iasplus.com/en/resources/ifrsf/history/resource25]. Следует отметить, что зачастую некоторые компании и органы, устанавливающие национальные стандарты бухгалтерской отчетности, напрямую использовали принципы, которые были разработаны IASC, но не прошли дальнейшее утверждение.

После того как IASC разработал стандарты, консультативная группа, второй компонент структуры комитета (Consultative Group), который включал в себя разнообразные международные организации, заинтересованные в бухгалтерском учете, давал совет относительно разработанных стандартов.

На следующем этапе принятия разработанных стандартов действовал постоянный комитет по интерпретации стандартов (Standing Interpretations Committee, или SIC). Главной функцией этого комитета были сбор и изложение общественного мнения относительно разработанных стандартов при предположении, что эти принципы окончательно утверждены.

Следующим компонентом структуры IASC был консультативный совет (Advisory Council), который являлся органом надзора.

И, наконец, в качестве последней инстанции стандартов (не столько разработки и принятия, сколько урегулирования и разрешения различных трудностей) были руководящие комитеты (Steering Committees), которые представляли собой экспертные целевые группы по различным проектам.

Спустя 24 года (в 1997 г.) IASC заключил, что необходимо сближение национальных стандартов бухгалтерского учета и высококачественных международных стандартов, которое невозможно без реструктуризации самого комитета и изменения его стратегии. В результате в конце 1997 г. началась работа по реструктуризации. Сначала была создана так называемая Стратегическая рабочая партия (Strategy Working Party), которая должна была пересмотреть структуру и стратегию комитета. В декабре 1998 г. Strategy Working Party резюмировала свою деятельность в отчет, представляющий собой рекомендации по изменению структуры и стратегии. После некоторых доработок в ноябре 1999 г. был представлен окончательный вариант, который был незамедлительно принят IASC. Остальные структуры IASC одобрили план в мае 2000 г. Таким образом, новая «конституция» IASC вступила в силу с 1 июля 2000 г.

Новая структура изображена на рисунке 1. Эта модель в своих некоторых важнейших отношениях основана на структуре Комитета (Совета) по стандартам финансового учета США (Financial Accounting Standard Board - FASB). Руководство - попечительский совет - изыскивает денежные средства, получая их из широкого спектра источников (включая корпорации, аудиторские фирмы и рыночные регулирующие органы) и назначает членов правления (International Accounting Standard Board - IASB), Консультативного совета по стандартам (Standards Advisory Council - SAC) и Комитета по интерпретациям (International Financial Reporting Interpretations Committee - IFRIC). Он контролирует также соответствие деятельности Правления его учредительным документам.

Правление Совета по МСФО (IASB) несет полную ответственность за все содержательные вопросы, включая подготовку и издание МСФО, их проектов, а также выносит окончательное решение об одобрении разъяснений (интерпретаций) к стандартам. Теперь консультаци- 
онный совет, комитет по интерпретациям и совет по разработке стандартов находятся под руководством IFRS Foundation, который в свою очередь управляется 22 попечителями. Функции этого органа очень широки и разнообразны, поэтому перечислим лишь некоторые из них: разработка в интересах общества набора высококачественных, понятных и повсеместно воспринимаемых стандартов финансовой отчетности, которые снабжены механизмами к исполнению (эти стандарты должны быть прозрачны, ясны, сопоставимы и полезны для пользователей финансовой отчетности); способствование повсеместному использованию и применению этих стандартов; содействие более легкой адаптации стандартов; назначение членов IASB, SAC и IFRIC и т.д. [http://www.iasplus.com/en/resources/ifrsf/governance/ifrsf]. IASC, переименованный в IASB, должен разрабатывать и публиковать международные стандарты высокого качества, которые будут обеспечивать прозрачность и сравнимость финансовых отчетностей компаний. Консультативный совет должен давать консультации IASB относительно приоритетных направлений, сообщать ему о применении стандартов и об общественном мнении относительно разработанных стандартов. И, соответственно, комитет по интерпретациям занимается разработкой интерпретаций международных стандартов и регламентацией иных вопросов [http://www.iasplus.com/en/resources/ifrsf/governance/ifrsf].

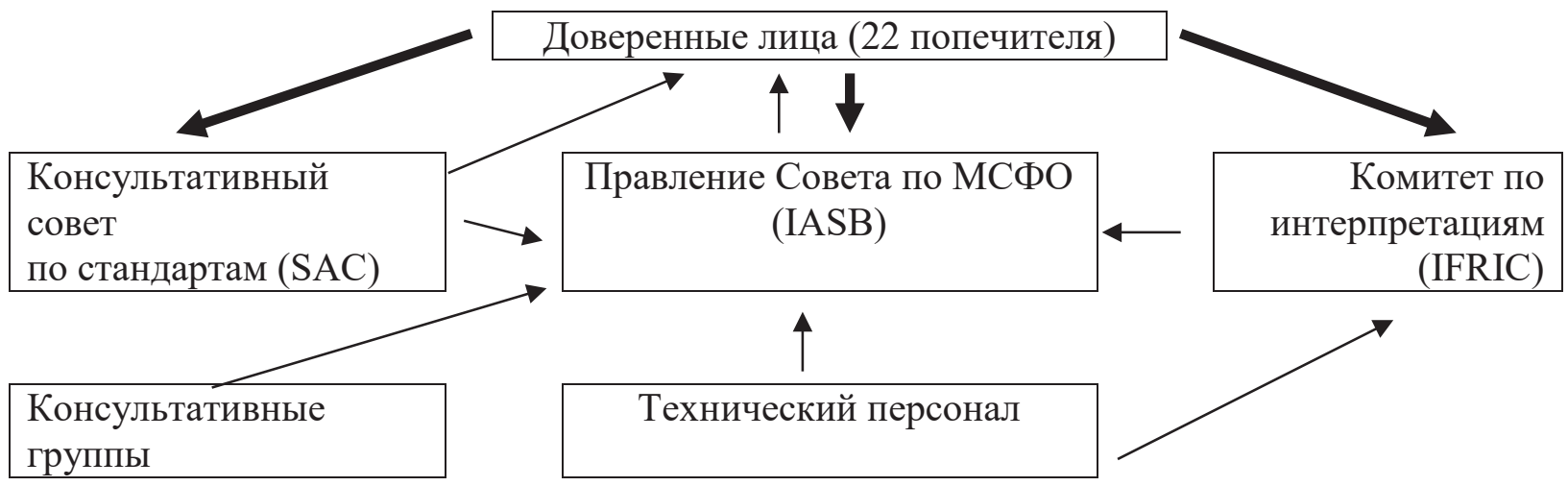

Рисунок 1. Структура Правления Совета по МСФО.

Примечание. Толстые стрелки представляют собой право попечителей назначать на соответствующую должность. Тонкие стрелки показывают информационные потоки (консультации, обратную связь, информацию).

Итак, мы видим, что новая структура комитета по международным стандартам финансовой отчетности, которая базируется главным образом на IASB, действительно способствует более эффективному функциональному распределению и выполнению первоначальных задач.

Настоящая система предназначена для того, чтобы позволить правлению разработать набор высококачественных стандартов финансовой отчетности, приемлемый для использования на международных рынках ценных бумаг и способный послужить моделью для сближения различных систем национальных стандартов. Для этого правлению потребуется убедить национальные органы, обладающие соответствующими функциями, одобрить использование международных стандартов: у правления нет для этого собственных прямых полномочий. Важным моментом для этого было одобрение IOSCO списка МСФO, но IOSCO просто рекомендует своим членам принять международные стандарты; что вовсе не обязывает их к этому. Американская Комиссия по ценным бумагам и биржам является ведущим участником IOSCO, и ее требование, чтобы использование международных стандартов на американских рынках сопровождалось пересчетом в соответствии с американским национальными стандартами, представляет собой главное препятствие для распространения МСФО. По этой причине очень важна реализуемая в настоящий момент программа внесения в МСФО и американские национальные стандарты ряда изменений, обеспечивающих их сближение. Кроме того, правление Совета по МСФО и Комитет по стандартам финансовой отчетности США взяли на себя обязательство по поиску лучших решений по определенным вопросам. Разработанные таким образом подходы будут реализованы и в МСФО, и в национальных стандартах США. Однако правление может столкнуться с препятствиями не только в США. Все страны или их 
регулирующие органы в ходе принятия Международных стандартов финансовой отчетности постараются, вероятно, сохранить за собой какое-то право вето или выбора, позволяющее избежать применения тех аспектов МСФО, которые будут сочтены ими неприемлемыми. При широком применении такого права оно может поставить под вопрос саму возможность достижения настоящей международной сравнимости. Прецедентным случаем в этом отношении может стать решение Европейской комиссии относительно IAS 32 и IAS 39 (стандарты по финансовым инструментам). В настоящее время Комиссия одобрила все другие стандарты, унаследованные СМСФО от организации-предшественника, но эти два столкнулись с сильным сопротивлением в Европе, особенно со стороны банков, и одобрение MCФО (IAS) 32 и MCФО (IAS) 39 было отсрочено до внесения в них заключительных поправок [Малофеева, 2006].

\section{Выпуск первых стандартов}

Прежде чем перейти к описанию первых стандартов, выпущенных IASC, следует отметить небольшую особенность: до реструктуризации комитета (т.е. до 2000-2001 гг.) международные стандарты выпускались под названием IAS (International Accounting Standards); после изменения структуры комитета стандарты, выпускаемые уже не IASC, a IASB, именовались IFRS (International Financial Reporting Standards) [Академия PwC, 2015, с. 15-18].

Так как в данной части работы мы рассматриваем работу IASC в период с 1973 г. по 2002 г., кратко изучим первые стандарты, выпущенные комитетом в этот период (т.e. IFRS, выпущенные IASB, и IAS, выпущенные позднее 2001-2002 гг., не будут рассматриваться; краткое изучение стандартов обусловлено тем, что это не является главной целью данной работы).

Первый стандарт (IAS) 1 «Представление финансовой отчетности» вступил в силу 1 января 1975 г., однако новая версия этого стандарта, учитывающая изменения, разработанные в 2007 г., повторно вступила в силу с 1 января 2009 г. Главной целью этого положения является сопоставимость финансовой отчетности компании за предшествующие периоды и финансовой отчетности других организаций. (IAS) 1 включает в себя информацию о рекомендации по структуре и минимальных требованиях к содержанию и предоставлению финансовой отчетности [Академия $\mathrm{PwC}, 2015$, с. 34-58].

Позже, в 1978 г., был опубликован (IAS) 8 «Учетные политики, изменения в бухгалтерских оценках и ошибки» (новая версия (IAS) 8, включающая последние изменения, вступила в действие с 1 января 2005 г.). Данный стандарт используется, когда компания выбирает, принимает и изменяет свою учетную политику, изменяет расчетные бухгалтерские оценки и исправляет ошибки, выявленные в предшествующих периодах.

(IAS) 10 «События после отчетной даты» действует с 1 января 1980 г. и учитывает изменения 2005 г. Данный стандарт описывает правила учета и отражения в финансовой отчетности событий, которые произошли в период после окончания отчетного периода и перед утверждением финансовой отчетности, подготовленной компанией.

С 1 января 1981 г. вступил в силу (IAS) 12 «Налоги на прибыль» (учтены изменения 1998 г.), который устанавливает порядок учета налогов на прибыль, а именно текущих и будущих налоговых последствий.

(IAS) 16 «Основные средства» был введен в действие с января 1983 г. с учетом изменения от 2005 г. Данный стандарт описывает принципы учета основных средств.

В 1984 г. в силу вступили два стандарта: (IAS) 17 «Аренда», который описывает принципы учета и «раскрытия информации в отношении финансовой и операционной аренды для арендаторов и арендодателей», и (IAS) 20 «Учет государственных субсидий и раскрытие информации о государственной помощи», который определяет порядок учета государственных субсидий и их отражение в финансовой отчетности.

Аналогично в 1985 г. были выпущены два стандарта: (IAS) 19 «Вознаграждения работникам», который описывает порядок учета вознаграждений работников и раскрытие этой ин- 
формации; и (IAS) 21 «Влияние изменений валютных курсов», раскрывающий информацию о порядке включения операций, выполненных в иностранной валюте, и зарубежной деятельности в финансовую отчетность, а также о переводе финансовой отчетности в валюту предоставления.

(IAS) 23 «Затраты по займам» и (IAS) 24 «Раскрытие информации о связанных сторонах» были выпущены в 1986 г. Первый стандарт учитывает изменения 2009 г. и устанавливает разрешаемый уровень капитализации затрат по займам, которые понесены из-за привлечения средств для финансирования покупки активов [Академия PwC, 2015, с. 189]. Второй стандарт учитывает изменения 2011 г. и определяет условия и порядок отражения информации об операциях со связанными сторонами (т.е. с дочерними и зависимыми компаниями) в финансовой отчетности (данная предосторожность необходима в силу того, что такие операции могут влиять на деятельность компании, на ее финансовый результат, а также на оценку деятельности компании пользователями финансовой отчетности).

В 1988 г. вступил в силу (IAS) 26 «Учет и отчетность по пенсионным планам», учитывающий изменения 1998 г. и отражающий, как оценивать и раскрывать информацию о пенсионных планах в финансовой отчетности.

В 1990 г. начали действовать (IAS) 28 «Инвестиции в ассоциированные и совместные предприятия», который описывает порядок учета таких инвестиций; и (IAS) 29 «Финансовая отчетность в гиперинфляционной экономике», устанавливающий, что финансовая отчетность на момент отчетной даты должна быть предоставлена в текущих валютных единицах (т.е. валюта страны с гиперинфляционной экономикой является функциональной валютой предприятия).

В 1993 г. и 1994 г. были опубликованы соответственно (IAS) 2 «Запасы», который должен был вступить в силу с 1 января 2005 г. и который устанавливал правила учета товарно-материальных запасов; и (IAS) 7 «Отчет о движении денежных средств», вступивший в силу непосредственно с 1994 г., описывающий изменение денежных средств предприятия за период и разделяющий потоки денежных средств на финансовую, операционную и инвестиционную деятельность.

В 1995 г. был выпущен (IAS) 32 «Финансовые инструменты: представление информации», усовершенствованный вариант которого повторно вступил в действие в 2005 г. Этот стандарт содержит требования к представлению информации о финансовых инструментах, которые являются финансовыми обязательствами или инструментами капитала, а также требования к взаимозачету финансовых инструментов.

(IAS) 33 «Прибыль на акцию» был опубликован в 1997 г. и должен был вступить в силу с 1999 г. Данный стандарт определяет, как нужно рассчитывать базовую и разводненную прибыль на акцию.

В 1998 г. был выпущен (IAS) 39 «Финансовые инструменты: признание и оценка», изменения которого вступили в силу в 2005 г. (действие этого стандарта ограничено 2018 г., впоследствии он будет заменен на IFRS 9) и который устанавливает правила оценки, признание и прекращения признания финансовых активов и обязательств.

И, наконец, ряд стандартов был выпущен в 1999 г.: (IAS) 34 «Промежуточная финансовая отчетность», устанавливающий минимальные требования к содержанию, правила бухгалтерского признания и оценки; (IAS) 36 «Обесценение активов», который заключается в установке процедуры, которую компания применяет для того, чтобы учитывать свои активы по величине, не превышающей их возмещаемой стоимости; стандарт также определяет, когда компания должна восстановить (реверсировать) убыток от обесценения актива и предписывает определенные требования к раскрытию информации; (IAS) 37 «Резервы, условные обязательства и условные активы» и (IAS) 38 «Нематериальные активы», который отражает порядок учета таких активов.

Таким образом, мы видим, что за период с 1973 г. по 2000 г. Комитетом по международным стандартам финансовой отчетности была сделана масштабная работа по разработке ключе- 
вых стандартов. Однако главным шагом на пути к распространению и внедрению разработанных принципов в США было Норволкское соглашение (Norwalk agreement), подписанное в 2002 г. IASB и FASB, которое наметило первые стремления к конвергенции двух стандартов.

\section{Развитие конвергенции МСФО и US GAAP в период деятельности администрации Джорджа Буша (2002 г. - январь 2009 г.)}

Джордж Буш-младший вступил на пост президента США 20 января 2001г., и с его приходом ассоциируется начало развития тесных отношений между IASB и FASB [McEnroe and Sullivan, 2014, p. 15], которое началось, как было упомянуто выше, с Норволкского соглашения (формально эти отношения начались еще в феврале 2000 г., когда SEC выпустила концепт релиза (Concept Release) на IAS, обращаясь к обществу с просьбой о выделении тех элементов, которые, с их точки зрения, должны быть подвержены конвергенции).

Очевидно, что и до подписания соглашения множество европейских компаний действовали на территории Соединенных Штатов Америки. На каких условиях они работали? В первую очередь новые европейский компании, пришедшие на американский рынок капитала, должны были регистрироваться у SEC, которая представляет собой главный орган надзора и регулирования рынка ценных бумаг. Зарубежные компании должны были следовать тем же правилам и нести те же обязательства, что и американские компании, однако первые пользовались некоторыми привилегиями. В частности, зарубежные эмитенты обязаны были предоставлять годовую отчетность в течение шести месяцев после окончания отчетного периода, в то время как домашние участники американского рынка ценных бумаг должны были предоставлять годовую отчетность только в течение трех месяцев после окончания финансового года. Но несмотря на это послабление со стороны SEC, европейские компании должны были составлять финансовую отчетность либо в соответствии с US GAAP, либо в соответствии с локальными GAAP, т.е. с упрощенными стандартами МСФО, которые были интерпретированы специально для европейских компаний (local GAAP), с приложением к отчетности согласования с US GAAP. Таким образом, компании затрачивали не только колоссальные человеческие ресурсы, но и огромные денежные суммы, что вело в конечном счете к нежеланию многих европейских компаний входить на американский рынок ценных бумаг. В условиях начинающейся конвергенции остро встал вопрос о возможности преодоления данной проблемы (заинтересованность США в данном случае заключается в том, что при нежелании зарубежных компаний участвовать на американском рынке капитала образуется недоинвестирование). Это был еще один стимул на пути к конвергенции стандартов.

Значительный этап в мире бухгалтерского учета начался с Директивы 2002/51/ЕС Европейского парламента и Совета ЕС от 19 июля 2002 г. (точнее, идея о разработке этой Директивы зародилась на Европейском Совете в Лиссабоне в 2000 г.), в соответствии с которой все публичные компании ЕС были обязаны составлять финансовую отчетность в соответствии с MCФО начиная с 2005 г. Уже с 1995-2000 гг. IOSCO вела свой проект основных стандартов (Core Standards Project), который заключался в рекомендации применения МСФО международными компаниями. В результате в 2002 г. IASB и FASB подписали Меморандум взаимопонимания (Memorandum of Understanding), который был нацелен на гармонизацию двух систем стандартов и их совместную работу над развитием и установлением необходимых принципов (председатель SEC, Гарви Питт, одобрил Меморандум и намеченные в нем цели в своем публичном выступлении).

Позднее, в 2005 г., Дональд Николасон, главный бухгалтер SEC, впервые упомянул о так называемой дорожной карте (roadmap) взаимоотношений между IASB и FASB (план по развитию конвергенции) в своей статье «А Securities Regulator Looks at Convergence» [McEnroe and Sullivan, 2014]. Этот план включал в себя условия, предпосылки и ключевое требование для достижения принятия МСФО SEC (оно представляло собой необходимость одинакового качества финансовых отчетностей, составленных, с одной стороны, в соответствии с US GAAP, и, с другой стороны, в соответствии с IFRS). Кроме того, в плане впервые упоминалась возможность не предоставлять европейскими компаниями документа согласования с US GAAP. 
Вопрос о необходимости ликвидации документа согласования с US GAAP получил свое дальнейшее развитие во время визита представителя Европейского союза, Чарли Маккриви, к SEC в феврале 2006 г. В ходе визита обе стороны подтвердили свое отношение к этому вопросу. В это же время SEC публично заявляет о своем намерении проверять финансовые отчетности тех компаний, которые составили их в соответствии с МСФО, начиная со второго полугодия 2006 г. В августе этого же года SEC и Комитет европейских регуляторных органов ценных бумаг (Committee of European Securities Regulators, далее - CESR) подписали соглашение о совместной работе, которое является фундаментом их дальнейшей кооперации.

2007 г. является следующим знаменательным этапом в истории бухгалтерского учета. В феврале председатель SEC Кэтлин Каси выступила в Институте юридической практики (Practicing Law Institution). В своей речи она заявила о том, что главной целью SEC также остается сохранение и гарантия ясного, эффективного и конкурентного рынка капитала, а также защита американских инвесторов; вместе с тем SEC продолжает работу по намеченному плану (roadmap), составленному в 2005 г., анализируя и отслеживая процесс конвергенции двух систем учета вместе с зарубежными эмитентами и регуляторными органами и обеспечивая тем самым правильное и последовательное применение и интерпретацию IFRS. B марте состоялся круглый стол по МСФО, на котором собрались руководство отдела главного бухгалтера, подразделения корпоративных финансов, представители различных образований рынка ценных бумаг с целью обсудить план развития конвергенции US GAAP и МСФО (roadmap). В результате было отмечено, что главной целью SEC до сих пор является ликвидация документа согласования с US GAAP, однако эта цель не означает полную конвергенцию двух систем учета (т.е. US GAAP не должны быть заменены на МСФО). 27 апреля 2016 г. состоялась встреча представителей SEC (Кристофера Кокса) и CESR (Эдди Вымирша), на которой были подведены итоги совместной работы за прошедший период (следует напомнить, что соглашение о совместной работе этих организаций было подписано в августе 2006 г.) и намечены основные цели и задачи дальнейшего взаимодействия.

Если мы вернемся в февраль 2006 г., то вспомним, что SEC объявила о своем намерении проверять финансовую отчетность европейских компаний, предоставленную в соответствии с MCФО, как было отмечено выше. Таким образом, к концу II квартала 2007 г. SEC проанализировала более 100 отчетностей, которые были составлены в соответствии с МСФО в первый раз. В результате этой проверки SEC была вынуждена отослать письма с просьбой объяснить многие аспекты предоставленной финансовой отчетности. Кроме того, еще до этого SEC отмечала, что существует примерно 30 различных версий МСФО (с разной интерпретацией, установленной локальной или региональной юрисдикцией). В итоге было принято решение, что, если и отменять документ согласования с US GAAP и разрешать, следовательно, европейским компаниям предоставлять финансовую отчетность в соответствии с МСФО, то только в том случае, если эта финансовая отчетность выполнена в соответствии с МСФО, выпущенными именно IASB, но не МСФО, которые являются упрощением и адаптацией ЕС или иных локальных или региональных юрисдикций.

Результатом всех этих соглашений, встреч, обсуждений стало Правило принятия от зарубежных частных эмитентов финансовых отчетностей, подготовленных в соответствии с МСФО без документа согласования с US GAAP (Acceptance from Foreign Private Issuers of Financial Statements Prepared in Accordance with IFRS without Reconciliation to US GAAP [McEnroe and Sullivan, 2014, p. 134], принятое и опубликованное 2 июля 2007 г. Под этим правилом SEC подразумевала главным образом то, что только те европейские компании, которые подготавливают финансовую отчетность в соответствии с МСФО в том виде, в котором их выпустил IASB, освобождаются от необходимости предоставления документа согласования с US GAAP (т.е. те компании, которые использовали иную версию МСФО, также должны были предоставлять документ согласования с US GAAP). Правило вступало в силу с окончанием отчетного года - после 15 ноября 2007 г. (т.е. компании имели право подготавливать финансовую отчетность без документа согласования уже за 2007 г.). Исключением были компании, которые использовали МСФО, упрощенные ЕС по стандарту (IAS) 39 «Финансовые инструменты: признание и 
оценка». Таким компаниям было разрешено предоставлять финансовую отчетность по такой версии МСФО в течение двух лет, при условии что они будут предоставлять документ согласования с MCФО, выпущенными IASB. По прошествии двух лет такие компании должны либо использовать IASB-версию МСФО, либо снова предоставлять документ согласования с US GAAP.

После того как это правило вступило в силу, следующим шагом на пути к конвергенции US GAAP и МСФО стало намерение SEC, объявленное в августе 2008 г., требовать от всех зарегистрированных американских компаний принимать МСФО (например, план разрешал крупным американским ТНК, рыночная капитализация которых составляет примерно 2,5 трлн долларов, использовать МСФО с 2010 г., однако ото всех американских публичных компаний требовалось использование МСФО начиная с 2014 г.). Это намерение, названное «Roadmap for the potential use of financial statements prepared in accordance with international financial statements by US issuers», было утверждено председателями в ноябре 2008 г.

Вскоре, 20 января 2009 г., новым президентом США стал Барак Обама. Вместе с его приходом в Белый дом закончился период тесных взаимоотношений IASB и FASB, а кроме того, развитие конвергенции US GAAP и МСФО заметно приостановилось и приобрело скорее характер застоя, нежели какого-либо движения.

\section{Застой конвергенции IFRS и US GAAP в период деятельности адми- нистрации Барака Обамы (январь 2009 г. -- конец 2012 г.)}

В январе 2009 г. на смену Джорджу Бушу-младшему пришел Барак Обама. С деятельностью его администрации условно связывают начало застоя, или замедление развития отношений между IASB и FASB (McEnroe and Sullivan, 2014, p. 15). Для того чтобы проверить, так ли это, посмотрим, как развивались отношения между двумя советами в период 2009-2012 гг.

Первым заметным действием SEC по вопросу конвергенции двух систем учета стала встреча в феврале 2010 г., на которой члены комиссии единогласно выразили поддержку установлению единых мировых стандартов, обладающих высоким качеством, а также заявили, что именно МСФО отвечает этим требованиям [Erchinger, 2012, p. 249]. Однако, как заявил председатель SEC, прежде чем принять окончательное решение по вопросу включения МСФО в американскую систему представления финансовой отчетности, необходимо полностью выполнить цели и задачи Меморандума взаимопонимания [Erchinger, 2012, p. 249]. В это же время SEC объявляет своим сотрудникам план работы, в соответствии с которым последние должны оценить, во-первых, стоит ли включать МСФО в американскую систему учета, и, вовторых, если да, то как и когда это необходимо осуществить (следует напомнить, что в 2000 г. $\mathrm{SEC}$ проводила похожее мероприятие). Итогом этой встречи стал релиз Положения комиссии в поддержку конвергенции и мировых стандартов учета (Commission Statement in Support of Convergence and Global Accounting Standards), который установил, что не ранее 2015 г. или 2016 г. будет произведена полная адаптация МСФО [McEnroe and Sullivan, 2014, p. 16]. Однако эта дата не должна восприниматься как абсолютно точная, так как данное положение содержало в себе только примерную дату начала адаптации МСФО, но не то, каким именно образом будет она проводиться. Тем не менее, несмотря на очевидное желание SEC установить дату принятия МСФО как можно позже, комиссия заявила, что надеется на дальнейшее сотрудничество FASB c IASB с целью улучшения американских стандартов [Erchinger, 2012, p. 249]. В это же время заместитель главного бухгалтера SEC, Пауль Бесвик, впервые упомянул о возможном варианте конвергенции МСФО и US GAAP, заявив, что «США не должны следовать конвергенции или одобрению» [McEnroe and Sullivan, 2014, p. 16], скорее они должны выбрать совершенно иной модифицированный вариант - condorsement.

Этот вариант внедрения МСФО в американскую систему учета подробнее был описан в мае 2011 г., когда SEC опубликовала документ «Work plan for the consideration of incorporating international financial reporting standards into the financial reporting system for US issuers: exploring a possible method of incorporation [McEnroe and Sullivan, 2014, p. 16-17]. Что же значит про- 
цесс condorsement? Это слово является производным от слов «convergence» и «endorsement». Первое слово, которое переводится как конвергенция, означает, что органы, устанавливающие национальные стандарты учета, будут приближать их локальные стандарты с МСФО в течение какого-то периода времени [Erchinger, 2012, р. 251]. Второе слово, которое переводится как «одобрение», означает, что локальные юрисдикции должны использовать установленные критерии для одобрения новых стандартов, выпущенных IASB. То есть этот подход предусматривает конвергенцию тех американских стандартов, которые не были еще подвержены этому процессу, и решения FASB относительно того, принимать или нет новые стандарты IASB [McEnroe and Sullivan, 2014, p. 16].

Документ, упомянутый выше, содержал в себе процедуру, с одной стороны, сохранения американских стандартов, а с другой стороны, конвергенции МСФО и US GAAP в течение определенного периода времени (точный срок конвергенции не был установлен, однако по оценкам руководства переходный период займет от пяти до семи лет [Erchinger, 2012, p. 252]. План переходного периода включал в себя три фазы: 1-я фаза: Завершение проектов Меморандума взаимопонимания. IASB и FASB по-прежнему были нацелены на полное выполнение всех поставленных целей и задач. Если совместная работа проходит успешно и проекты будут выполнены, то последние будут внедрены в US GAAP и МСФО в ближайшее время, оказав при этом минимальное воздействие на текущий план.

2-я фаза: Оценивание FASB новых стандартов IASB. FASB должен оценивать стандарты, выпущенные IASB, чтобы определить, в какой степени эти стандарты меняют МСФО и как сильно они отличаются от US GAAP. Когда IASB будет окончательно публиковать стандарты, FASB должен отдельно рассматривать каждый стандарт, чтобы наилучшим образом внедрить его в американскую систему учета.

3-я фаза: Включение МСФО, которые не входили в проекты двух предыдущих фаз. На этом этапе FASB должен оценивать те стандарты, которые не были включены в проекты Меморандума взаимопонимания и которые не являются на повестке дня IASB, с целью дальнейшей конвергенции этих стандартов в US GAAP.

Данный план переходного периода, который не устанавливает конкретные сроки проведения всех трех фаз, а значит, не определяет точную дату конвергенции МСФО, имеет большое преимущество: он позволяет избежать так называемого большого взрыва (big bang), который представляет собой необходимость американских эмитентов принимать абсолютно все МСФО сразу; кроме того, план помогает сохранить и закрепить за американскими стандартами статус нормативной основы для предоставления финансовой отчетности, а также ввести мораторий на любые новые стандарты FASB.

В июле 2012 г. SEC выпустила окончательный вариант «Work plan for the consideration of incorporating international financial reporting standards into the financial reporting system for US issuers: final staff report», в котором, во-первых, не было отражено никакой позиции SEC по отношению к процессу конвергенции МСФО в US GAAP (т.е. SEC так и не решила, стоит ли проводить конвергенцию вообще и, если да, то как и когда); и, во-вторых, не отвечал, является ли вообще переход на МСФО главным приоритетом американского рынка ценных бумаг и американских инвесторов в частности, а вместо этого отражал, что необходим дополнительный анализ последствий принятия SEC окончательного решения. Таким образом, мы можем наблюдать явную неуверенность SEC в том, что принятие МСФО является хорошим решением.

Очевидно, что такое неоднозначное решение SEC (или скорее его отсутствие) вызвало поспешную реакцию. Как заявил председатель IASB Хегурворст: «Эра конвергенции подошла к концу...»

В декабре 2012 г. слова Зидмана отразили окончательную позицию США по процессу конвергенции МСФО и US GAAP. Зидман сказал, что Соединенные Штаты не могут полностью полагаться (даже в долгосрочной перспективе) на стандарты, фундаментом которых являются 
только лишь принципы ${ }^{2}$, и что цель достижения 100\%-ной сопоставимости финансовых отчетностей не является достижимой в ближайшем будущем [McEnroe and Sullivan, 2014, p. 19].

Таким образом, мы можем наблюдать, что в период деятельности администрации Барака Обамы тенденция конвергенции двух систем учета приняла скорее обратное направление, нежели в период работы администрации Буша. В 2002-2009 гг. ранее начатые отношения между IASB и FASB развивались очень стремительно, однако случившееся в 2009 г. торможение отношений переросло к 2012 г. в застой.

\section{Заключение}

1. В данной работе была предпринята попытка проанализировать развитие конвергенции US GAAРиМСФОпоэтапно, результатыкотороймогутдатьответнаследующиевопросы: Так ли идеальны МСФО, как может показаться на первый взгляд?

2. Обладают ли американские и международные стандарты учета одинаковым качеством?

3. Готов ли мир в целом и США в частности к высоким темпам интеграции и унификации стандартов учета?

Как было показано в работе, в период с 2002 г. по 2009 г. США были готовы к скорой конвергенции двух систем учета, о чем свидетельствуют тесные взаимоотношения двух главных советов - IASB и FASB, результатом которых стало постановление множества планов, целей, отмена документа согласования с US GAAP и общее признание МСФО как единственно возможных стандартов, представляющих высокое качество работы IASB, который, объединяя стандарты разных стран, разрабатывая новые и совершенствуя итоговые стандарты, стремится получить высококачественные и надежные стандарты, создавая тем самым унифицированный мир бухгалтерского учета.

Однако критика в адрес набирающей обороты конвергенции была высказана и в период деятельности администрации Джорджа Буша-младшего. В частности, в 2007 г. бывший главный бухгалтер SEC Лин Тернер заявил, что успех конвергенции мог бы быть достигнут только в случае действительной сопоставимости двух систем учета, однако слишком много «дыр» имеется в руководстве по ведению учета в разных отраслях [McEnroe and Sullivan, 2014, p. 16]. Также председатель SEC Мэри Шапиро, назначенная Бараком Обамой, в начале 2009 г. выразила обеспокоенность относительно стоимости перехода на другой режим учета, которую придется заплатить компаниям (по оценкам SEC, такие затраты могут достигнуть 32 млн долларов для некоторых предприятий) [McEnroe and Sullivan, 2014, p. 16] и относительно независимости IASB (т.е. независимая разработка и принятие стандартов, а также их конвергенция с US GAAP ставились под сомнение ввиду структуры IASC, о которой было рассказано выше, а также из-за возможности независимого финансирования комитета). Кроме того, было высказано опасение относительно неустойчивой природы МСФО, которые базировались исключительно на принципах.

Период с 2009 г. по конец 2012 г. отличается, наоборот, неготовностью Соединенных Штатов к таким темпам конвергенции. Результатом такой неготовности стало приостановление сближения двух стандартов (формально SEC выработала план перехода на новые стандарты, однако точная дата этого перехода не была озвучена). По мнению SEC, требовался дополнительный анализ МСФО, их влияния на американский рынок ценных бумаг и инвесторов после окончательного принятия МСФО, а также разницы между US GAAP и МСФО.

Что касается вопросов о качестве международных и американских стандартов учета, то для определения применимости МСФО в мире SEC проанализировала финансовые отчетности 183 компаний, расположенных в 22 странах (компании были выбраны из списка Fortune Global 5002009 г.; 80\% этих компаний были расположены на территории ЕС, также были

\footnotetext{
${ }^{2}$ Главной разницей между US GAAP и IFRS является то, что первые базируются на правилах (около 17000 страниц правил), а последние - на принципах (всего 2500 страниц) [Hlaciuc, Grosu, Socoliuc, and Maciuca, 2014, c. $141]$.
} 
представлены компании Австралии, Бразилии и Китая), которые подготавливали финансовую отчетность в соответствии с МСФО [Erchinger, 2012, p. 254]. Однако анализ SEC был ограничен информацией, открытой в финансовой отчетности; в частности, во многих случаях руководство SEC просто не могло определить, как некоторые сделки были отображены в отчетности и соответствует ли учетная политика компании МСФО. В результате этого анализа руководство заключило, что в целом финансовые отчетности соответствуют требованиям МСФО, однако ясность и прозрачность сделок некоторых компаний и раскрытие информации о применяемой учетной политике могут быть улучшены (т.е. некоторые компании не предоставляли информацию об учетной политике в определенных сферах деятельности, также не были предоставлены уточняющие детали учетной политики, которые могли бы помочь инвесторам и иным пользователям полно и ясно понять финансовую отчетность. Кроме того, использовалась терминология, отличная от установленной терминологии МСФО). Также SEC заключила, что разнообразное применение МСФО создает сложности в сопоставимости и сравнении финансовых отчетностей разных отраслей и разных стран.

Более того, как уже отмечалось выше, сама база МСФО - принципы - может быть причиной создания стандартов не такого высокого качества, как того требуют Соединенные Штаты, т.е. в то время как US GAAP базируется на правилах, предоставляя точное руководство относительно большинства операций компаниям из совершенно разных отраслей, МСФО предлагает скудное, неточное и необширное руководство особенно для некоторых отраслей (например, отрасли страхования) [McEnroe and Sullivan, 2014, p. 17-19]. Как заявил Зидман, финансовая система США требует большей точности, чем может предложить МСФО [McEnroe and Sullivan, 2014, p. 19].

Подводя итог, следует сказать, что, во-первых, как показало исследование SEC, MCФO не являются высококачественными стандартами, так как многие положения могут быть усовершенствованы; во-вторых, в некоторых случаях US GAAР являются более качественными, нежели МСФО (причина может корениться в разной основе МСФО и US GAAP, а также в финансовой культуре США, которая многие годы основывалась исключительно на правилах, но не действовала исходя из принципов); и, в-третьих, что в разные периоды США по-разному были настроены на интеграцию систем учета. Некоторые авторы видят причину изменения направления отношения SEC и США в целом к конвергенции в мировом финансовом кризисе, начавшемся в 2008 г. и в результате которого появились совершенно иные приоритетные цели. Однако оба периода были необходимы для того, чтобы выявить слабые места МСФО и органов, разрабатывающих и принимающих их, ибо экономическая глобализация только набирает обороты, а это значит, что совсем скоро может возникнуть острая необходимость в унифицированных высококачественных стандартах учета, хотя уже сейчас существует эта необходимость. Попытка конвергенции двух качественных стандартов учета привела к тому, что МСФО будут совершенствоваться дальше, чтобы стать основой для единого мира бухгалтерского учета.

\section{Список литературы}

1. Академия РwС. Учебное пособие АССА ДипИФР. 2015. Available at: http://training.pcw. ru/courses/dipifr_materials/

2. Малофеева Т.Н. Цели и задачи Совета по Международным стандартам финансовой отчетности // Сборник статей аспирантов факультета экономики ГУ - ВШЭ. М.: Издательство Государственный университет - Высшая школа экономики, 2006.

3. Deloitte. МСФО в кармане. 2015. Available at: www2.deloitte.com/ru/ru/pages/audit/ articles/IFRS-in-your-pocket-2015.html

4. Ernst \& Young. Применение МСФО 2011. В 3 частях. М.: Альпина Паблишер, 2011.

5. Norwalk Agreement. Available at: http://www.fasb.org/news/memorandum.pdf.

6. Brown P. and Tarca A. (2005) A commentary on issues relating to the enforcement of 
International Financial Reporting Standards in the EU. European Accounting Reviews, vol. 14, no. 1 .

7. Erchinger H. (2012) IFRS and the United States - Developments and Current States. Australian Accounting Review, vol. 22.

8. Erchinger H. and Melcher W. Convergence between US GAAP and IFRS: acceptance of IFRS by the US securities and exchange commission (SEC). Accounting in Europe, vol.4

9. Hlaciuc E., Grosu V., Socoliuc M., Maciuca G. (2014) Comparative study regarding the main differences between US GAAP and IFRS. The USV Annals of Economics and Public Administration, 2014, vol.14.

10. McEnroe J/E. and Sullivan M. (2014) The rise and stall of the US GAAP and IFRS Convergence Movement. The CPA Journal, January.

11. Leuz C.(2003) IAS versus U.S. GAAP: information asymmetry-based evidence from Germany`s New Market. Journal of Accounting Research, vol. 41, pp. 451-472.

12. Melcher W. (1999) «Konvergenz des internen und externen Rechnungswesens»// Internationale Rechnungslegung, Springer, 2nd edn, p.363

13. Schipper K. (2005) The introduction of international accounting standards in Europe: implications for international convergence. European Accounting Reviews, vol. 14, no. 1, pp. 101-126.

\title{
THE EMERGENCE AND DEVELOPMENT OF THE CONVERGENCE PROCESS OF THE TWO TYPES OF STANDARDS: IFRS AND US GAAP
}

\author{
Tatiana Malofeeva \\ Lecturer at Department of Finance \\ National research University Higher school of Economics \\ email:malofeewa@mail.ru
}

\begin{abstract}
It is well known that economy is the foundation on which the state stands, and what it will be depends on the nature of economic processes in the country. One of the factors to the favorable economic climate is the creation of suitable conditions for the emergence and development of transnational corporations (TNCs). For the productive work of TNCs required standards in accordance with which the company, first, maintains its accounting records, and, secondly, provides financial statements to different users. The difficulty in this case is, on the one hand, to lead the company's activities and to provide information about the financial performance of the company in accordance with the principles of the host countries, i.e. countries in which the property is located TNCs and, on the other hand, to perform the same action only in accordance with the principles of the home country, i.e. the country in which the headquarters of TNCs. In this paper the analysis of the gradual formation and development of the process of convergence of the two types of standards: US generally accepted accounting standards (US GAAP) and international financial reporting standards (IFRS). It was found that in various periods the rate of convergence had changed considerably, caused by the change of leadership in the White House. Identified weaknesses of IFRS and justified the international community's readiness to the high speed of globalization.
\end{abstract}

Keywords: IFRS, US GAAP, convergence, comparison, globalization 
1. Akademija PwC (2015) Uchebnoe posobie ACCA DipIFR [Study text ACCA DipIFR]. Available at: http://training.pcw.ru/courses/dipifr_materials.

2. Malofeeva T.N. (2006) Celi i zadachi Soveta po Mezhdunarodnym standartam finansovoj otchetnosti [Goals and Objectives of International Accounting Standards Board] // V kn.: Sbornik statej aspirantov fakul'teta jekonomiki GU - VShJe. Gosudarstvennyj universitetVysshaja shkola jekonomiki.

3. Deloitte (2015) MSFO v karmane [IFRS in Your Pocket], Available at: www2.deloitte.com/ ru/ru/pages/audit/articles/IFRS-in-your-pocket-2015.html

4. Ernst \& Young (2011) Primenenie MSFO 2011 v 3-h chastjah [Adoption of IFRS 2011 in three parts]. Mockow: Al'pina Pablisher, 2011

5. “Norwalk Agreement” Available at: http://www.fasb.org/news/memorandum.pdf

6. Brown P. and Tarca A. (2005) A commentary on issues relating to the enforcement of International Financial Reporting Standards in the EU. European Accounting Reviews, vol. 14, no. 1 .

7. Erchinger H. (2012) IFRS and the United States - Developments and Current States. Australian Accounting Review, vol. 22.

8. Erchinger H. and Melcher W. Convergence between US GAAP and IFRS: acceptance of IFRS by the US securities and exchange commission (SEC). Accounting in Europe, vol.4

9. Hlaciuc E., Grosu V., Socoliuc M., Maciuca G. (2014) Comparative study regarding the main differences between US GAAP and IFRS. The USV Annals of Economics and Public Administration, 2014, vol.14.

10. McEnroe J/E. and Sullivan M. (2014) The rise and stall of the US GAAP and IFRS Convergence Movement. The CPA Journal, January.

11. Leuz C. (2003) IAS versus U.S. GAAP: information asymmetry-based evidence from Germany`s New Market. Journal of Accounting Research, vol. 41, pp. 451-472.

12. Melcher W. (1999) Konvergenz des internen und externen Rechnungswesens. Internationale Rechnungslegung, Springer, $2^{\text {nd }}$ edn, p. 363.

13. Schipper K. (2005) The introduction of international accounting standards in Europe: implications for international convergence. European Accounting Reviews, vol. 14, no. 1, pp. 101-126.

\title{
ОТРАЖАЮТ ЛИ ЗАКОНОДАТЕЛЬНО РАЗРЕШЕННЫЕ СПОСОБЫ ОСУЩЕСТВЛЕНИЯ ВЕНЧУРНЫХ ИНВЕСТИЦИЙ НА ФОРМАЛЬНЫХ РЫНКАХ КАПИТАЛА РОССИЙСКОЙ ФЕДЕРАЦИИ ИХ ЭКОНОМИЧЕСКУЮ СУЩНОСТЬ?
}

Макушина Елена Юрьевна

\begin{abstract}
Цель данной работы - определить термин «венчурные инвестиции» с точки зрения его экономической сущности и на основании этого определения исследовать нормативно-законодательную базу, регулирующую реализацию инвестиций на формальном рынке венчурного капитала в Российской Федерации, с тем чтобы предложить возможные рекомендации по ее усовершенствованию.
\end{abstract}

Для достижения поставленной цели в работе были сформулированы и решены следующие задачи: выявлены три подхода к определению венчурных инвестиций; проанализированы

${ }^{1}$ Старший преподаватель департамента финансов, факультета экономических наук НИУ ВШЭ E-mail: emakushina@hse.ru 